\title{
Tsafon
}

Revue d'études juives du Nord

$75 \mid 2018$

Exil des langues - Langues d'exil

\section{Élie Buzyn, J'avais 15 ans. Vivre, survivre, revivre}

\section{Danielle Delmaire}

\section{(2) OpenEdition}

Journals

Édition électronique

URL : https://journals.openedition.org/tsafon/751

DOI : $10.4000 /$ tsafon.751

ISSN : 2609-6420

\section{Éditeur}

Association Jean-Marie Delmaire

\section{Édition imprimée}

Date de publication : 1 juin 2018

Pagination : 187-188

ISSN : 1149-6630

\section{Référence électronique}

Danielle Delmaire, «Élie Buzyn, J'avais 15 ans. Vivre, survivre, revivre», Tsafon [En ligne], 75 | 2018, mis en ligne le 06 mai 2019, consulté le 23 juin 2021. URL : http://journals.openedition.org/tsafon/751 ; DOI : https://doi.org/10.4000/tsafon.751

Ce document a été généré automatiquement le 23 juin 2021.

Tsafon. Revues d'études juives du Nord 


\title{
Élie Buzyn, J'avais 15 ans. Vivre, survivre, revivre
}

\author{
Danielle Delmaire
}

\section{RÉFÉRENCE}

Élie Buzyn, J'avais 15 ans. Vivre, survivre, revivre, Paris, Alisio, 2018, 157 p., $18 €$

1 Élie Buzyn appartient à ce groupe d'adolescents qui furent déportés à Auschwitz et qui ont réussi à survivre malgré leur extermination programmée, souvent en trichant sur leur âge dès leur arrivée pour ne pas être dirigés immédiatement vers les chambres à gaz. Parmi les plus connus qui ont, comme Élie Buzyn, raconté leur douloureux

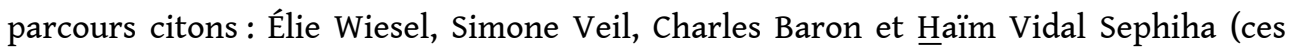
deux derniers ont accepté de publier leurs témoignages dans Tsafon, $\mathrm{n}^{\circ} \mathrm{73}$, printempsété 207, p. 29-38 et 39-46). Ils sont connus car, malgré les blessures qui ne se sont jamais cicatrisées, ils sont parvenus à mener une carrière honorable. C'est le cas aussi du jeune Élie Buzyn qui devint chirurgien-orthopédiste reconnu (il est le père de l'actuelle ministre Agnès Buzyn).

2 Pour ces adolescents, trois étapes jalonnent leur vie : " vivre, survivre, revivre ». Pour Élie Buzyn, la première étape se déroule à Lodz où il naquit en 1929. Mais très vite, il faut survivre, dès l'enfermement dans le ghetto où le jeune garçon âgé de 11 ans devint le soutien de sa famille ravagée par la fusillade d'un autre fils, sous ses yeux, en guise d'avertissement. Puis c'est la survie à Auschwitz, entretenue par le souvenir et la fidélité à l'injonction de sa mère : "Tu dois tout faire pour rester en vie » (p. 36). Les historiens n'ont peut-être pas assez souligné, chez ces condamnés à l'extermination, cette résistance morale, dignité humaine à opposer à la force de déshumanisation imposée par les nazis: c'est le souvenir d'un chant alors qu'ils n'entendent que hurlements, d'une recette de cuisine alors qu'ils sont affamés, d'un ciel radieux alors que les nuages lourds de neige assombrissent leur horizon... 
3 C'est cette résistance morale qui animait aussi Charlotte Rosenberg qui exigeait de ses enfants, dans le camp de Ravensbrück, une toilette quotidienne, même rudimentaire, pour être dignes et ne point se laisser aller (lire la recension du livre de Lili Leignel). Fort de cette résistance, Élie Buzyn peut écrire: «Notre survie représentait une affirmation du droit des Juifs à la vie; se suicider était collaborer à notre propre extermination » (p.51). La solidarité entre déportés prouvait aussi qu'ils n'étaient pas encore deshumanisés, même parmi des prisonniers allemands victimes eux aussi de la barbarie nazie.

4 Enfin, il faut revivre après la déportation et la perte des parents. Le retour est chaotique : un passage en Israël, une installation en France durant laquelle le jeune Élie cherche encore sa voie professionnelle. Mais enfin, la réussite est complète tant professionnellement que personnellement grâce à la famille fondée avec Etty malgré «...les affres de ma difficile reconstruction" (exergue p.9) car: «Cette victoire sur l'adversité représente pour moi l'échec total du projet des nazis de nous éliminer » (p 13). Revivre et se reconstruire ne furent guère chose aisée, à commencer par supporter le tatouage du nombre d'immatriculation sur l'avant-bras, tatouage qu'il a fait enlever : bout de peau conservé précieusement et perdu malencontreusement. Et pourtant son passé a souvent guidé ses décisions prises dans le temps présent d'après la guerre, notamment en ce qui concerne ses patients.

5 Le témoignage, bref (une centaine de pages) mais sobre et allant à l'essentiel est suivi du témoignage de membres de sa famille dont son épouse qui l'a aidé dans cette troisième étape : « revivre ", d'amis dont le grand rabbin ㅂaïm Korsia. La réussite du « revivre » est matérialisée par la photo du 10 février 2018 sur laquelle Élie Buzyn brandit d'une main une veste rayée de déporté et de l'autre la veste qu'il avait revêtue lorsqu'il reçut la flamme olympique, à Grenoble, le 6 février 2006. 